\title{
Writing in a Polyaniline Film with Laser Beam and Stability of the Record: A Raman Spectroscopy Study
}

\author{
Zuzana Morávková (iD) and Patrycja Bober \\ Institute of Macromolecular Chemistry, Czech Academy of Sciences, Heyrovsky Sq. 2, Prague, Czech Republic \\ Correspondence should be addressed to Zuzana Morávková; moravkova@imc.cas.cz
}

Received 30 May 2018; Accepted 3 September 2018; Published 4 October 2018

Academic Editor: Bernabé L. Rivas

Copyright ( 2018 Zuzana Morávková and Patrycja Bober. This is an open access article distributed under the Creative Commons Attribution License, which permits unrestricted use, distribution, and reproduction in any medium, provided the original work is properly cited.

Lines were drawn on polyaniline (PANI) salt films with laser beam, and then the samples were left to age in air at room temperature. Both the irradiated and intact parts of the sample and their ageing were studied with Raman spectroscopy. It was found that the laser-written record is reasonably stable. The degradation of polyaniline by laser irradiation and ageing was compared to the changes in PANI during heating. In all cases, deprotonation and crosslinking of PANI chains proceed but the relative rates of the processes vary with degradation conditions.

\section{Introduction}

Conducting polymers, such as polyaniline (PANI), are widely studied due to their ease of preparation, good level of electrical conductivity, redox and ion-exchange properties, and environmental stability [1-8]. However, the understanding of the stability and the mechanism of degradation of polyaniline is of great importance for possible applications [9-13].

When PANI salt is exposed to elevated temperature, the changes at the molecular level manifest themselves by the loss of doping acid molecules and formation of phenazinelike or quinonoid segments [9]. Besides the chemical changes, conformation is changed by thermal treatment [14]. This feature is an inherent property of PANI and is not influenced by the nature of the protonating acid. Similar processes take place in PANI salt during ageing at room temperature $[15,16]$.

The changes in the molecular structure of PANI which occur during heating can be conveniently observed by Raman spectroscopy [17-19]. When the excitation laser line falls within the region of a permitted electronic transition of the sample, the Raman intensities associated with vibrational modes coupled with the excited electronic states can be markedly increased due to a resonance effect. The Raman features of semiquinone radical structures typical for protonated emeraldine salt are enhanced by near-infrared excitation; in contrast, the Raman features of quinonoid units typical for the PANI base are enhanced with a red excitation line [20].

PANI strongly absorbs in the Vis-NIR region; thus, the samples can be locally heated by the irradiation. Deprotonation, degradation, and possible carbonization may occur during Raman spectrum recording [21, 22]. These degradation ways-ageing, heating, and laser irradiation-do have similar effects on PANI $[9,21,22]$, but this has not been directly compared.

The possibility to locally deprotonate a PANI film with laser beam opens an interesting opportunity for organic electronics. Conducting paths of PANI salt films can be separated by lines of the deprotonated PANI base. In this work, the writing on a PANI film with laser beam and ageing of the record are studied. Raman spectra of chemically and thermally deprotonated PANI films are compared with the PANI film after laser irradiation and ageing in air.

\section{Materials and Methods}

2.1. Preparation of PANI Films. Polyaniline was prepared by the oxidation of $0.2 \mathrm{M}$ aniline hydrochloride (Fluka, Switzerland) with $0.25 \mathrm{M}$ ammonium peroxydisulfate (APS) (Lach-Ner, Czech Republic) in water [23] at room temperature. The films were deposited in situ on glass and goldcoated glass windows, $13 \mathrm{~mm}$ in diameter. A couple of films 
was deprotonated with an excess of $1 \mathrm{M}$ ammonium hydroxide to the PANI base. The films were then rinsed with acetone and dried in air.

2.2. Heating. PANI films were heated in ceramic oven in a nitrogen atmosphere (thermal degradation). The heating was switched on, and the temperature was increased at $22^{\circ} \mathrm{C} \cdot \mathrm{min}^{-1}$. After $100^{\circ} \mathrm{C}$ was reached, the heating was switched off and the sample was left to cool, still in the flowing nitrogen stream.

2.3. Ageing. PANI films were left in air at room temperature and analysed at selected times up to two months.

2.4. Laser Irradiation. Lines were drawn on PANI-S films with $1064 \mathrm{~nm}$ excitation laser of the Thermo Nicolet 6700 FTIR spectrometer with a silicon-coated calcium fluoride beam splitter and NXR FT-Raman module with a microscope accessory by simply moving the sample stage of the microscope continuously at two different speeds while simultaneously observing in white light and irradiating with the laser. Laser degradation was also induced by $514 \mathrm{~nm}$ and $633 \mathrm{~nm}$ excitation lasers of various powers by irradiation of separated spots.

2.5. Spectroscopic Characterization. Raman spectra excited in the visible range with a HeNe 633 and Ar-ion $514 \mathrm{~nm}$ laser were collected on the Renishaw inVia Reflex Raman spectroscope. The research-grade Leica DM LM micrometer with an objective magnification of $\times 50$ was used to focus the laser beam on the sample placed on an X-Y motorized sample stage. The scattered light was analyzed by the spectrograph with a holographic grating with 1800 or 2400 lines $\mathrm{mm}^{-1}$. A Peltier-cooled CCD detector $(576 \times 384$ pixels $)$ registered the dispersed light.

\section{Results and Discussion}

3.1. Raman Spectra of Intact PANI-S Films. The Raman spectrum of PANI hydrochloride films was measured with 514, 633 , and $785 \mathrm{~nm}$ excitation lines (Figure 1). It is expected that the vibrations originating from quinonoid units should be resonance enhanced with a laser excitation wavelength at $633 \mathrm{~nm}[24,25]$; however, these structures are present in the PANI-S only in a very low content and their features are not observed in the spectrum. On the other hand, the typical bands of PANI-S, mainly at 1595, 1504, 1335, and $1182 \mathrm{~cm}^{-1}$, are present. Positions and assignments of all the present bands are listed in Table 1.

In the Raman spectrum of PANI hydrochloride films excited with the $514 \mathrm{~nm}$ laser line (Figure 1, green line), in contrast with the spectrum obtained with the $633 \mathrm{~nm}$ excitation line, the most intense peak in the ring stretching region is observed at $1620 \mathrm{~cm}^{-1}$ and in the $\mathrm{C}-\mathrm{H}$ deformation region at $1194 \mathrm{~cm}^{-1}$; these bands are connected with benzenoid units [26]. This excitation line is not in resonance with any form of PANI; thus, the band intensity follows the concentration of benzenoid/quinonoid rings more reliably.

Using the $785 \mathrm{~nm}$ excitation line (Figure 1, black line), different semiquinone radical structures attributed to the

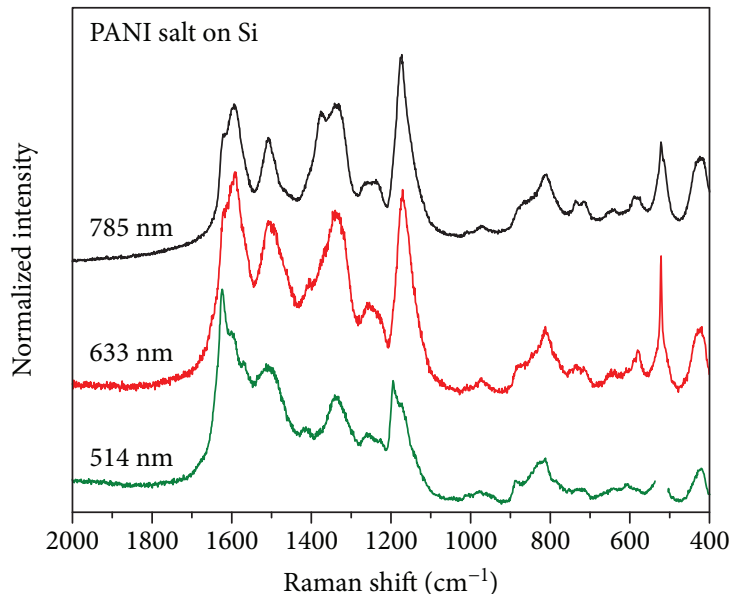

Figure 1: Raman spectra of intact PANI hydrochloride films on silicon support obtained with 514, 633, and $785 \mathrm{~nm}$ laser lines.

$\mathrm{C} \sim \mathrm{N}^{+\bullet}$ vibration of variously localized polaronic sites are resonantly enhanced. The spectrum is close to the spectrum excited with the $633 \mathrm{~nm}$ line; significant changes can be observed only in the group of bands connected with $\mathrm{C} \sim \mathrm{N}^{+}$ stretching vibrations, where a band at $1377 \mathrm{~cm}^{-1}$ connected with semiquinonoid rings with lower polaron delocalization can be observed in addition to the delocalized polaron band at $1335 \mathrm{~cm}^{-1}$.

3.2. Degradation by Laser Beam. PANI is rather sensitive to irradiation and can be damaged by laser beam during measurement [16]. The excitation wavelength at $514 \mathrm{~nm}$ is out of resonance with both PANI emeraldine salt and base, but the photon energy is high. With this excitation line, long accumulation at low laser power is necessary to obtain acceptable quality of the spectra without any damage to the sample. The spectra change quickly with increasing laser power (Figure 2(a)).

At laser power up to $10 \%$, the band at $1335 \mathrm{~cm}^{-1}$ decreased and the band at $575 \mathrm{~cm}^{-1}$ increased. These changes can be attributed to partial deprotonation and formation of phenazine-like structures $[15,22]$. At higher intensities, the bands broadened, bands at 514, 1402, and $1620 \mathrm{~cm}^{-1}$ disappeared, the band at $575 \mathrm{~cm}^{-1}$ shifted to $560 \mathrm{~cm}^{-1}$, and the band at $1335 \mathrm{~cm}^{-1}$ decreased significantly. Further deprotonation, random crosslinking, and bond breakage take place $[15,44]$.

The excitation at $633 \mathrm{~nm}$ is in resonance with quinonoid structures, so partial deprotonation of PANI-S is detected easily (Figure 2(b)). Raman spectra can be safely obtained without damage to the sample at higher power, than with that of the green line. The Raman spectra of PANI-S measured with the $633 \mathrm{~nm}$ line of HeNe laser were obtained in acceptable quality without any damage to the sample. At higher laser power, the band at $430 \mathrm{~cm}^{-1}$ shifted to $419 \mathrm{~cm}^{-1}$; peaks at $577 \mathrm{~cm}^{-1}, 607 \mathrm{~cm}^{-1}, 730 \mathrm{~cm}^{-1}, 1230 \mathrm{~cm}^{-1}, 1400 \mathrm{~cm}^{-1}$, and $1600 \mathrm{~cm}^{-1}$ increased; and bands at $1566 \mathrm{~cm}^{-1}$ and $1638 \mathrm{~cm}^{-1}$ appeared. The band at $1170 \mathrm{~cm}^{-1}$ and shoulder at $1470 \mathrm{~cm}^{-1}$ decreased. These changes are connected with deprotonation of the sample [45]. 
TABle 1: Assignment of the Raman bands of PANI.

\begin{tabular}{lcc}
\hline $\begin{array}{l}\text { Band position } \\
\left(\mathrm{cm}^{-1}\right)\end{array}$ & Assignment & References \\
\hline 1640 & Phenazine-like crosslinking & {$[22]$} \\
1620 & $\mathrm{C} \sim \mathrm{C}$ stretching vibrations of the phenylene ring & {$[24,27-31]$} \\
1595 & $\mathrm{C} \sim \mathrm{C}$ stretching vibrations of the semiquinonoid ring \\
$1563-1558$ & $\mathrm{C}=\mathrm{C}$ stretching vibrations of the quinonoid ring & {$[27,29,32-36]$} \\
1504 & $\mathrm{~N}-\mathrm{H}$ deformation in the semiquinonoid structures & {$[27,29,32-36]$} \\
$1480-1468$ & $\mathrm{C}=\mathrm{N}$ stretching vibrations in quinonoid units & {$[30,33,34,37-39]$} \\
1415 & $\mathrm{C}-\mathrm{N}$ stretching in highly localized polaronic structures & {$[25,32]$} \\
1377 & $\mathrm{C} \sim \mathrm{N}^{+\bullet}$ stretching vibrations in highly localized polarons & {$[27,32,40]$} \\
1335 & $\mathrm{C} \sim \mathrm{N}^{+\bullet}$ stretching vibrations of the semiquinone cation radicals in delocalized polaronic & {$[32]$} \\
1257 & structures & {$[31,37,41]$} \\
1221 & C-N stretching in quinonoid structures & {$[24,31,42]$} \\
1194 & C-N stretching in benzenoid units & {$[24,31,42]$} \\
1182 & $\mathrm{C}-\mathrm{H}$ deformation vibration of a benzenoid ring & {$[32,35,36,39,43]$} \\
1164 & $\mathrm{C}-\mathrm{H}$ deformation vibration of a semiquinonoid ring & {$[32,35,36,39,43]$} \\
887 & $\mathrm{C}-\mathrm{H}$ deformation vibration of a quinonoid ring & {$[32,35,36,39,43]$} \\
834 & $\mathrm{C} \sim \mathrm{C}$ ring deformation vibration (out-of-plane) of the polaronic form & {$[29]$} \\
812 & $\mathrm{C} \sim \mathrm{C}$ ring deformation vibration (out-of-plane) in the quinonoid ring & {$[32]$} \\
780 & The benzene ring deformation in the emeraldine salt & {$[29]$} \\
751 & Ring deformation in the emeraldine base & {$[27,32]$} \\
608 & Ring deformation in the emeraldine base & {$[27,32]$} \\
575 & Phenylene ring torsion & {$[22,29,32]$} \\
533 & Phenazine-like crosslinking & {$[22]$} \\
417 & & {$[21]$}
\end{tabular}

The $1064 \mathrm{~nm}$ excitation is in resonance with $\pi$-polaron transition of PANI-S, and it is highly absorbed. In addition, the Raman cross-section is significantly lower at longer excitation wavelengths so higher power had to be used. As a result, it is practically impossible to obtain a Raman spectrum of nondamaged PANI-S with this excitation line. For this reason, the lines were first drawn on the PANI-S sample with the $1064 \mathrm{~nm}$ excitation line and then analyzed with the low-power $633 \mathrm{~nm}$ excitation line, which is, on the other hand, the gentlest way of PANI film measurement (Figure 2(c) and 2(d)). The fact that our FTRaman setup allows easy and controlled movement of the sample against the laser beam is an advantage for deliberate damage-drawing on the PANI-S film. The treated area changes its color and is visible even by the naked eye (fig Foto).

There are significant changes in the spectra when irradiated with the $1064 \mathrm{~nm}$ laser line. The irradiation with power up to $1 \mathrm{~W}$ with high-speed movement of the laser beam on the sample causes partial deprotonation and formation of phenazine-like crosslinks, as manifested by appearance of the bands at $1563,1463,1390$, and $606 \mathrm{~cm}^{-1}$. The irradiation with $0.2 \mathrm{~W}$ at low speed deprotonates the sample completely. Higher power causes transformation to amorphous carbon analogue $[9,46]$.

\section{Degradation by Ageing in Air}

The samples with the burned record were left to age in air. The lines on the films faded, as could be seen in Figure 3 . The changes of the PANI film at the line drawn with $0.2 \mathrm{~W}$ laser power at low speed (Figure 4) and out of the line (Figure 5) are well illustrated by the Raman spectra. The PANI-S film partially deprotonates by ageing, following the increase of intensity of Raman bands at $1470 \mathrm{~cm}^{-1}$ and $1223 \mathrm{~cm}^{-1}$ and the decrease of intensity of the bands at 1338 and $1257 \mathrm{~cm}^{-1}$. In addition, bands at $1376,780,750$, and $730 \mathrm{~cm}^{-1}$ appear and the band at $587 \mathrm{~cm}^{-1}$ shifts to $577 \mathrm{~cm}^{-1}$. This is connected with the formation of phenazine-like crosslinks [15]. However, the level of protonation is still high after two months.

The Raman spectra of the line burnt with the $1064 \mathrm{~nm}$ excitation wavelength do not change much during time. The shoulder at $1610 \mathrm{~cm}^{-1}$ increased, the band at $1470 \mathrm{~cm}^{-1}$ shifted to $1480 \mathrm{~cm}^{-1}$, and a small band appeared at $810 \mathrm{~cm}^{-1}$. The band at $1335 \mathrm{~cm}^{-1}$ increased slightly. All changes were already observed after two days and can be understood as stabilization of the thermally deprotonated sample. First, the volatile chloride anions are removed but the conformation and electron distribution are not yet changed accordingly, as suggested by the position of the $\mathrm{C}=\mathrm{N}$ 


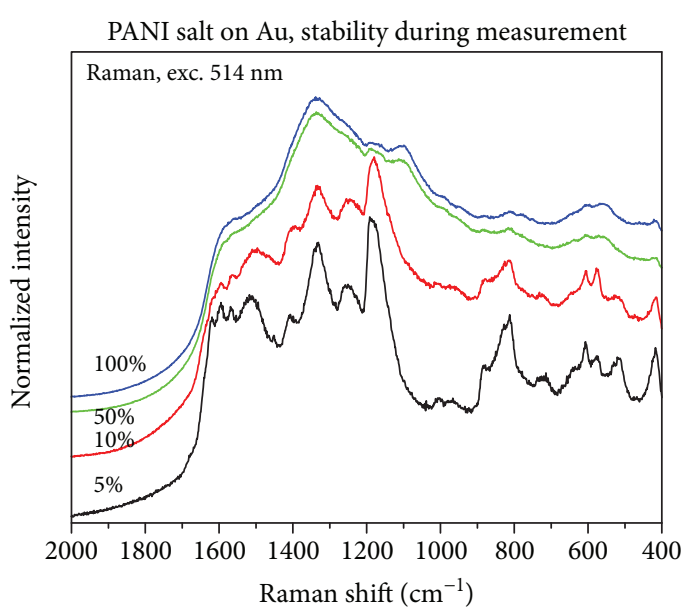

(a)

PANI salt on Au, stability on $1064 \mathrm{~nm}$ irradiation, low speed

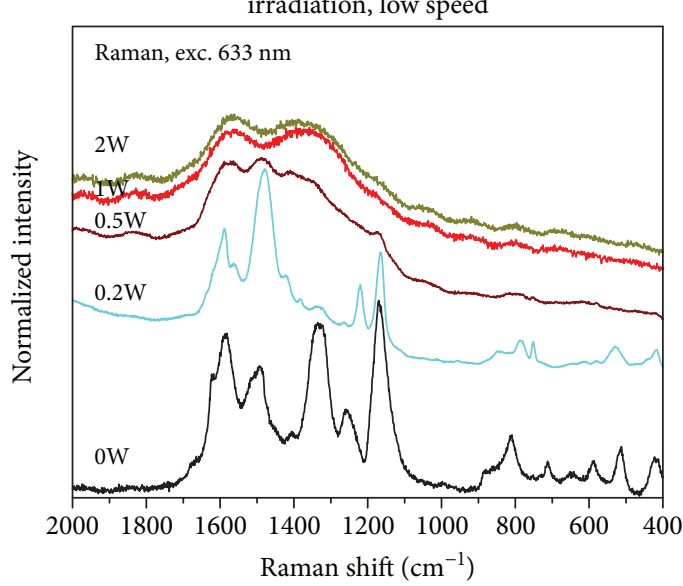

(c)

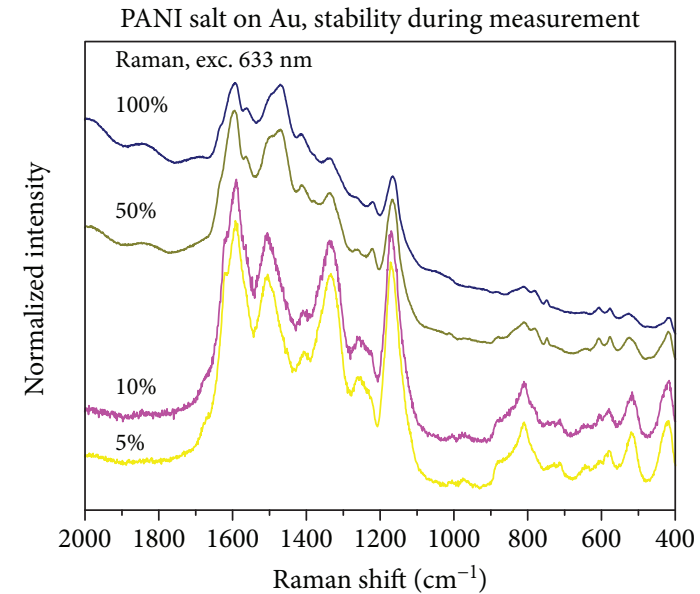

(b)

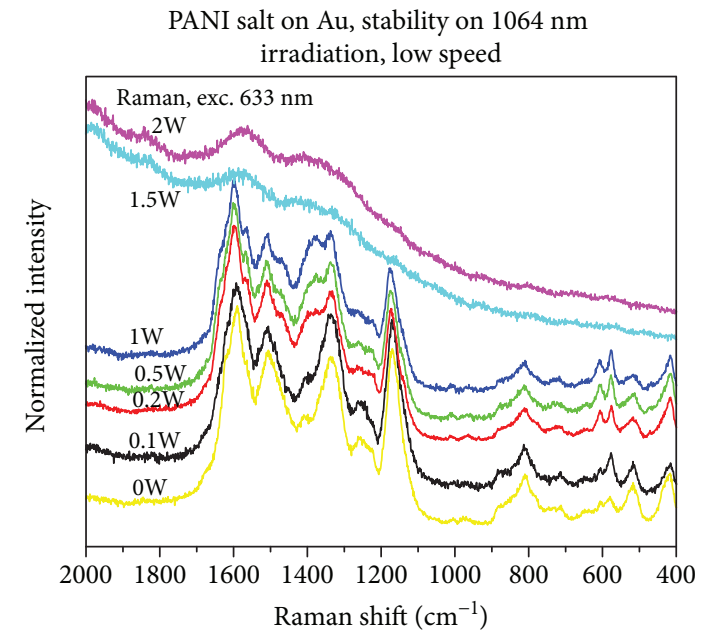

(d)

FIGURE 2: Raman spectra of a PANI film on gold support burned with various powers of 514, 633, and $1064 \mathrm{~nm}$ radiation (for burning with the $1064 \mathrm{~nm}$ line, the spectra were measured subsequently with the low-power $633 \mathrm{~nm}$ line).
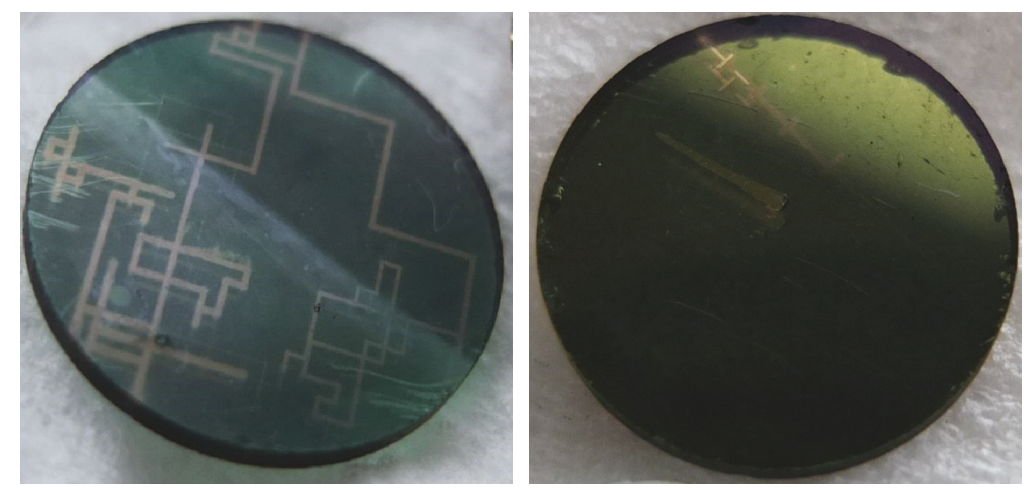

FIGURE 3: PANI-S on glass and gold with structures drawn with 1064 excitation laser. Line thickness varies from 40 to $100 \mu \mathrm{m}$ depending on the laser power (from 0.1 to $2 \mathrm{~W}$ ).

stretching band at $1478 \mathrm{~cm}^{-1}$ typical for short pernigranilinelike or phenazine-like oligomers [27, 32, 40] (C-C stretching in emeraldine salt is also present near this Raman shift $[29,47])$ and the strong dominance of the $\mathrm{C}=\mathrm{C}$ stretching band of quinonoid rings at $1560 \mathrm{~cm}^{-1}$ in the ring stretching region. Later, the band of benzenoid ring stretching at $1605 \mathrm{~cm}^{-1}$ appears and the $\mathrm{C}=\mathrm{N}$ stretching band shifts to the standard position for the PANI emeraldine base at $1468 \mathrm{~cm}^{-1}[25,32]$. These changes can be connected with conformational relaxation in the new deprotonated state. 


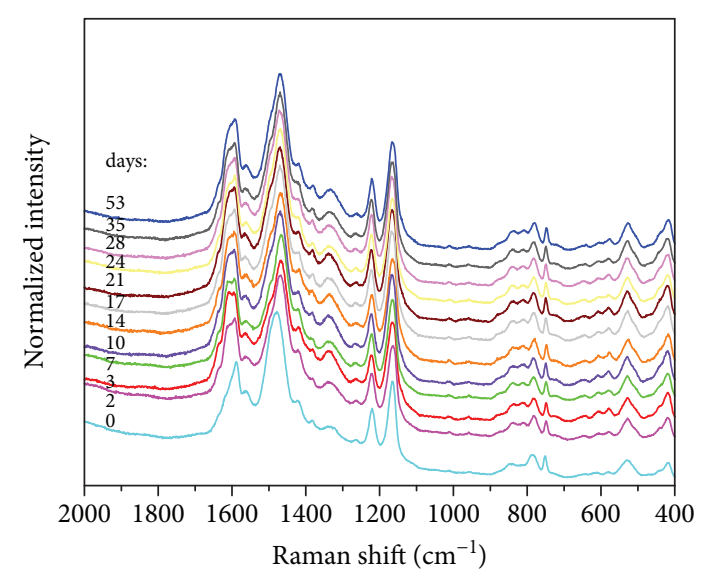

FIGURE 4: Raman spectra of a line burnt to the PANI-S film on gold with a $0.2 \mathrm{~W} 1064 \mathrm{~nm}$ laser line at low speed, obtained with the $633 \mathrm{~nm}$ excitation line at a marked time after burning. The samples were stored at room temperature in air.

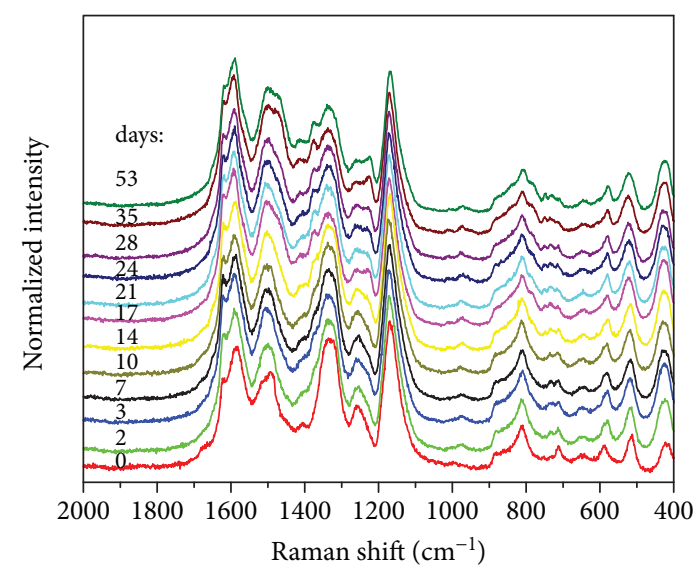

FIGURE 5: Raman spectra of the PANI-S film on gold obtained with the $633 \mathrm{~nm}$ excitation line at a marked time after preparation. The samples were stored at room temperature in air.

In fact, the already stabilized spectrum was observed before as the spectrum of thermally deprotonated PANI-S [46]. In this case, the spectra of the fresh record were measured within an hour after recording.

4.1. Degradation by Heating in Inert Atmosphere. Another method of PANI degradation which has been studied is heating in inert atmosphere (Figure 6). A PANI-S film on silicon support was heated to $100^{\circ} \mathrm{C}$ and analyzed with Raman spectroscopy [46]. The Raman spectrum obtained with the $633 \mathrm{~nm}$ laser displays mainly the increase of the bands connected with quinonoid structures (1595, 1558, 1468, 1415, and $1222 \mathrm{~cm}^{-1}$ ) that are resonantly enhanced and the decrease of the intensity of benzenoid $\left(1620,1257 \mathrm{~cm}^{-1}\right)$ and semiquinonoid structures $\left(1337 \mathrm{~cm}^{-1}\right)$ after heating the sample at $100^{\circ} \mathrm{C}$ [29]. The broad band of $\mathrm{C}=\mathrm{N}$ stretching vibrations in quinonoid units at $1480 \mathrm{~cm}^{-1}$ becomes the strongest band of the spectrum. The band connected with localized polarons at $1380 \mathrm{~cm}^{-1}$ appeared.

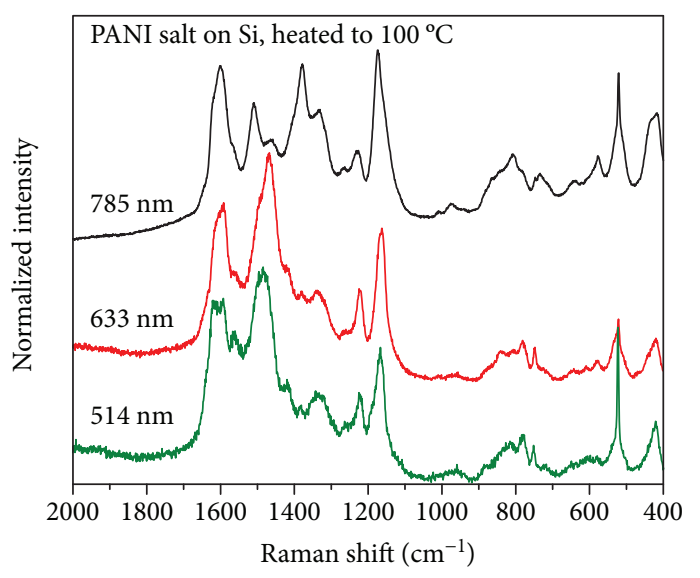

Figure 6: Raman spectra of the PANI film heated at $100^{\circ} \mathrm{C}$ in nitrogen atmosphere, excited with the 514, 633, and $785 \mathrm{~nm}$ laser line.

The Raman spectrum obtained with the $514 \mathrm{~nm}$ excitation line is very similar to the spectrum excited with the $633 \mathrm{~nm}$ line. This suggests that the quinonoid units are really dominant in the film and not just brought up by the resonance enhancement with the $633 \mathrm{~nm}$ excitation line.

With the $785 \mathrm{~nm}$ excitation, smaller changes of the spectrum of original PANI-S films are detected. The spectrum differs significantly from the spectra excited with visible laser lines. The semiquinonoid structures are resonantly enhanced with this excitation, so the main emeraldine salt character was preserved in the spectrum. A small band at $1465 \mathrm{~cm}^{-1}$, corresponding to the $\mathrm{C}=\mathrm{N}$ vibration in quinonoid units, appeared; the band at $1220 \mathrm{~cm}^{-1}$ increased relatively to the band at $1257 \mathrm{~cm}^{-1}$; and the intensity of the peak at $1330 \mathrm{~cm}^{-1}$ decreased while the band at $1378 \mathrm{~cm}^{-1}$ did not change and a small band at $1415 \mathrm{~cm}^{-1}$ appeared.

The changes in the Raman spectra correspond to partial deprotonation, which is sensitively detected with the $633 \mathrm{~nm}$ excitation, and to the formation of quinonoid and phenazine-like defects. On the defective sites, localization of polarons takes place, resulting in the Raman band of localized $\left(1380 \mathrm{~cm}^{-1}\right)$ and highly localized $\left(1400-1415 \mathrm{~cm}^{-1}\right)$ polarons.

4.2. Comparison of the Different Types of Degradation. During all kinds of degradation of PANI films, similar processes like deprotonation, crosslinking, or even carbonization took place; however, their rates differ.

Deprotonation is the dominant process when moderate energy flow is delivered to the sample, either by heating or by laser irradiation. The Raman spectra of heated and irradiated PANI-S films are virtually identical with the chemically deprotonated PANI film (Figure 7); only minor differences in the intensities of the bands of both quinonoid units and residual protonated units imply varying levels of deprotonation.

By simple ageing in air or low-power irradiation, the deprotonation is accompanied by the formation of phenazinelike crosslinks. These changes are gradual. On the other hand, the deprotonated sample does not undergo crosslinking during ageing in a detectable extent. Crosslinking takes 


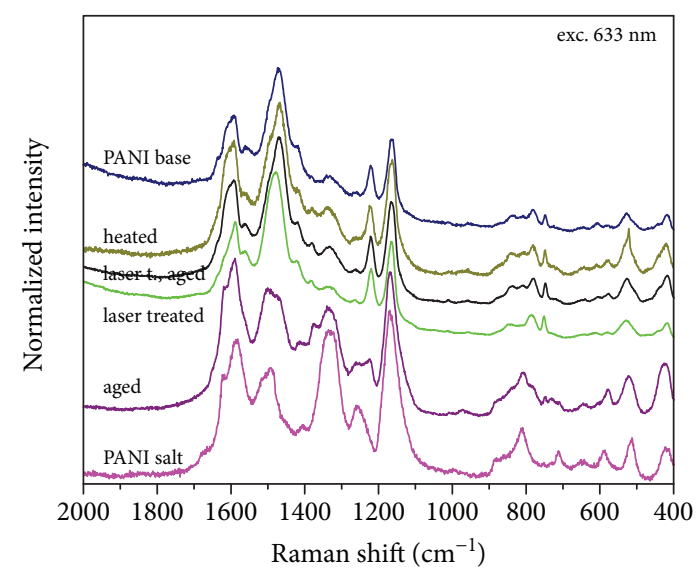

FIGURE 7: Comparison of degradation methods on a PANI-S film on gold. Raman spectra are obtained with the $633 \mathrm{~nm}$ excitation line.

place also during heating and irradiation, but only at a higher temperature [46].

\section{Conclusions}

All ways of PANI degradation, i.e., ageing in air, heating, and laser irradiation, led mainly to two effects, deprotonation and crosslinking. Strong laser irradiation or heating to temperature higher than $500^{\circ} \mathrm{C}$ [46] led even to carbonization of the film. The rates of these transformations varied for varying degradation conditions, but qualitatively, the processes were identical. Chemical deprotonation, however, proceeds in a different manner and has a different impact on the material stability [46-48].

Due to the different rates of degradations at different temperatures, accelerated ageing at increased temperature cannot be reliably used as a model of ageing at room temperature. At elevated temperatures, deprotonation is favored against crosslinking.

In the present paper, it is demonstrated that it is possible to write into a PANI film with a laser beam. The line thickness is large, in the order of tens of nanometers. Such low spatial resolution should be sufficient for certain applications in inexpensive electronics, such as RFID tags. The recorded pattern shows reasonable stability in air at room temperature.

\section{Data Availability}

All data (Raman spectra) used to support the findings of this study are included in the article.

\section{Conflicts of Interest}

The authors declare that they have no conflicts of interest.

\section{Acknowledgments}

Eliška Klimentová (secondary school student attending "Opened Science" project at Czech Academy of Sciences) is acknowledged for performing experimental work, and the Centre of Administration and Cooperation of Czech Academy of Sciences is thanked for organizing this project. The financial support from the Grantová Agentura Ceské Republiky (18-01924Y) is gratefully acknowledged.

\section{References}

[1] J. Stejskal, I. Sapurina, and M. Trchová, "Polyaniline nanostructures and the role of aniline oligomers in their formation," Progress in Polymer Science, vol. 35, no. 12, pp. 1420-1481, 2010.

[2] Z. A. Boeva and V. G. Sergeyev, "Polyaniline: synthesis, properties, and application," Polymer Science Series C, vol. 56, no. 1, pp. 144-153, 2014.

[3] Z. Tian, H. Yu, L. Wang et al., "Recent progress in the preparation of polyaniline nanostructures and their applications in anticorrosive coatings," RSC Advances, vol. 4, no. 54, p. 28195, 2014.

[4] T. H. Qazi, R. Rai, and A. R. Boccaccini, “Tissue engineering of electrically responsive tissues using polyaniline based polymers: a review," Biomaterials, vol. 35, no. 33, pp. 9068-9086, 2014.

[5] I. Fratoddi, I. Venditti, C. Cametti, and M. V. Russo, "Chemiresistive polyaniline-based gas sensors: a mini review," Sensors and Actuators B, vol. 220, pp. 534-548, 2015.

[6] P. Sengodu and A. D. Deshmukh, "Conducting polymers and their inorganic composites for advanced Li-ion batteries: a review," RSC Advances, vol. 5, no. 52, pp. 42109-42130, 2015.

[7] E. Kolasińska and P. Kolasiński, "A review on electroactive polymers for waste heat recovery," Materials, vol. 9, no. 6, p. 485, 2016.

[8] T. Sen, S. Mishra, and N. G. Shimpi, "Synthesis and sensing applications of polyaniline nanocomposites: a review," RSC Advances, vol. 6, no. 48, pp. 42196-42222, 2016.

[9] G. Ćirić-Marjanović, I. Pašti, N. Gavrilov, A. Janošević, and S. Mentus, "Carbonised polyaniline and polypyrrole: towards advanced nitrogen-containing carbon materials," Chemical Papers, vol. 67, no. 8, p. 781, 2013.

[10] S. Shrivastava, N. Jadon, and R. Jain, "Next-generation polymer nanocomposite-based electrochemical sensors and biosensors: a review," Trends in Analytical Chemistry, vol. 82, pp. 55-67, 2016.

[11] V. Giel, Z. Morávková, J. Peter, and M. Trchová, “Thermally treated polyaniline/polybenzimidazole blend membranes: Structural changes and gas transport properties," Journal of Membrane Science, vol. 537, pp. 315-322, 2017.

[12] Q.'e. Zhang, A.'a. Zhou, J. Wang, J. Wu, and H. Bai, “Degradation-induced capacitance: a new insight into the superior capacitive performance of polyaniline/graphene composites," Energy \& Environmental Science, vol. 10, no. 11, pp. 23722382, 2017.

[13] N. R. Tanguy, M. Thompson, and N. Yan, "A review on advances in application of polyaniline for ammonia detection," Sensors and Actuators B: Chemical, vol. 257, pp. 1044-1064, 2018.

[14] I. Šeděnková, J. Prokeš, M. Trchová, and J. Stejskal, “Conformational transition in polyaniline films - spectroscopic and conductivity studies of ageing," Polymer Degradation and Stability, vol. 93, no. 2, pp. 428-435, 2008.

[15] I. Šeděnková, M. Trchová, and J. Stejskal, “Conformational transition in polyaniline films - spectroscopic and conductivity 
studies of ageing," Polymer Degradation and Stability, vol. 93, no. 12, pp. 2147-2157, 2008.

[16] Z. Rozlívková, M. Trchová, I. Šeděnková, M. Špírková, and J. Stejskal, "Structure and stability of thin polyaniline films deposited in situ on silicon and gold during precipitation and dispersion polymerization of aniline hydrochloride," Thin Solid Films, vol. 519, no. 18, pp. 5933-5941, 2011.

[17] S. Mentus, G. Ćirić-Marjanović, M. Trchová, and J. Stejskal, "Conducting carbonized polyaniline nanotubes," Nanotechnology, vol. 20, no. 24, article 245601, 2009.

[18] M. Trchová, E. N. Konyushenko, J. Stejskal, J. Kovářová, and G. Ćirić-Marjanović, "The conversion of polyaniline nanotubes to nitrogen-containing carbon nanotubes and their comparison with multi-walled carbon nanotubes," Polymer Degradation and Stability, vol. 94, no. 6, pp. 929-938, 2009.

[19] A. Janosević, I. Pašti, N. Gavrilov et al., "Microporous conducting carbonized polyaniline nanorods: synthesis, characterization and electrocatalytic properties," Microporous and Mesoporous Materials, vol. 152, pp. 50-57, 2012.

[20] Y. Furukawa, F. Ueda, Y. Hyodo, I. Harada, T. Nakajima, and T. Kawagoe, "Vibrational spectra and structure of polyaniline," Macromolecules, vol. 21, no. 5, pp. 1297-1305, 1988.

[21] P. Colomban, S. Folch, and A. Gruger, "Vibrational study of short-range order and structure of polyaniline bases and salts," Macromolecules, vol. 32, no. 9, pp. 3080-3092, 1999.

[22] G. M. do Nascimento and M. L. A. Temperini, "Studies on the resonance Raman spectra of polyaniline obtained with near-IR excitation," Journal of Raman Specroscopy, vol. 39, no. 7, pp. 772-778, 2008.

[23] J. Stejskal and R. G. Gilbert, "Polyaniline. Preparation of a conducting polymer(IUPAC technical report)," Pure and Applied Chemistry, vol. 74, no. 5, pp. 857-867, 2002.

[24] T. Lindfors and A. Ivaska, "Raman based $\mathrm{pH}$ measurements with polyaniline," Journal of Electroanalytical Chemistry, vol. 580, no. 2, pp. 320-329, 2005.

[25] G. M. do Nascimento, P. Y. G. Kobata, R. P. Millen, and M. L. A. Temperini, "Raman dispersion in polyaniline base forms," Synthetic Metals, vol. 157, no. 6-7, pp. 247-251, 2007.

[26] G. Ćirić-Marjanović, M. Trchová, and J. Stejskal, “The chemical oxidative polymerization of aniline in water: Raman spectroscopy," Journal of Raman Specroscopy, vol. 39, no. 10, pp. 1375-1387, 2008.

[27] G. Louarn, M. Lapkowski, S. Quillard, A. Pron, J. P. Buisson, and S. Lefrant, "Vibrational properties of polyanilineisotope effects," The Journal of Physical Chemistry, vol. 100, no. 17, pp. 6998-7006, 1996.

[28] M. I. Boyer, S. Quillard, G. Louarn, G. Froyer, and S. Lefrant, "Vibrational study of the $\mathrm{FeCl} 3$-doped dimer of polyaniline; a good model compound of emeraldine salt," Physical Chemistry B, vol. 104, no. 38, pp. 8952-8961, 2000.

[29] M. Cochet, G. Louarn, S. Quillard, J. P. Buisson, and S. Lefrant, "Theoretical and experimental vibrational study of emeraldine in salt form. Part II," Journal of Raman Specroscopy, vol. 31, no. 12, pp. 1041-1049, 2000.

[30] Z. Wei, M. Wan, T. Lin, and L. Dai, "Polyaniline nanotubes doped with sulfonated carbon nanotubes made via a selfassembly process," Advanced Materials, vol. 15, no. 2, pp. 136139, 2003.

[31] G. Niaura, R. Mažeikien戸, and A. Malinauskas, "Structural changes in conducting form of polyaniline upon ring sulfonation as deduced by near infrared resonance Raman spectroscopy," Synthetic Metals, vol. 145, no. 2-3, pp. 105112, 2004

[32] M. I. Boyer, S. Quillard, E. Rebourt et al., "Vibrational analysis of polyaniline: a model compound approach," The Journal of Physical Chemistry. B, vol. 102, no. 38, pp. 7382-7392, 1998.

[33] J. E. P. da Silva, S. I. C. de Torresi, and M. L. A. Temperini, "Redox behavior of crosslinked polyaniline films," Journal of the Brazilian Chemical Society, vol. 11, no. 1, pp. 91-94, 2000.

[34] R. Mažeikiené, G. Niaura, and A. Malinauskas, "In situ Raman spectroelectrochemical study of electrocatalytic processes at polyaniline modified electrodes: redox vs. metal-like catalysis," Electrochemistry Communications, vol. 7, no. 10, pp. 10211026, 2005.

[35] M. C. Bernard and A. Hugot-Le Goff, "Quantitative characterization of polyaniline films using Raman spectroscopy: I. Polaron lattice and bipolaron," Electrochimica Acta, vol. 52, no. 2, pp. 595-603, 2006.

[36] M. C. Bernard and A. Hugot-Le Goff, "Quantitative characterization of polyaniline films using Raman spectroscopy: II. Effects of self-doping in sulfonated polyaniline," Electrochimica Acta, vol. 52, no. 2, pp. 728-735, 2006.

[37] J. E. P. da Silva, S. I. C. de Torresi, D. L. A. de Faria, and M. L. A. Temperini, "Raman characterization of polyaniline induced conformational changes," Synthetic Metals, vol. 101, no. 1-3, pp. 834-835, 1999.

[38] M. Tagowska, B. Palys, and K. Jackowska, "Polyaniline nanotubules-anion effect on conformation and oxidation state of polyaniline studied by Raman spectroscopy," Synthetic Metals, vol. 142, no. 1-3, pp. 223-229, 2004.

[39] G. M. do Nascimento, V. R. L. Constantino, R. Landers, and M. L. A. Temperini, "Aniline polymerization into montmorillonite clay: a spectroscopic investigation of the intercalated conducting polymer," Macromolecules, vol. 37, no. 25, pp. 9373-9385, 2004.

[40] M. Takahashi, M. Goto, and M. Ito, "Surface-enhanced Raman scattering of phenazine. large intensities of overtones and combination bands," Chemical Physics Letters, vol. 121, no. 45, pp. 458-463, 1985.

[41] R. Mažeikiené, A. Statino, Z. Kuodis, G. Niaura, and A. Malinauskas, "In situ Raman spectroelectrochemical study of self-doped polyaniline degradation kinetics," Electrochemistry Communications, vol. 8, no. 7, pp. 1082-1086, 2006.

[42] A. Buzarovska, I. Arsova, and L. Arsov, "Electrochemical synthesis of poly(2-methyl aniline): electrochemical and spectroscopic characterization," Journal of the Serbian Chemical Society, vol. 66, no. 1, pp. 27-37, 2001.

[43] G. M. do Nascimento, C. H. B. Silva, and M. L. A. Temperini, "Electronic structure and doping behavior of PANI-NSA nanofibers investigated by resonance Raman spectroscopy," Macromolecular Rapid Communications, vol. 27, no. 4, pp. 255-259, 2006.

[44] Z. Rozlívková, M. Trchová, M. Exnerová, and J. Stejskal, “The carbonization of granular polyaniline to produce nitrogencontaining carbon," Synthetic Metals, vol. 161, no. 11-12, pp. 1122-1129, 2011.

[45] M. Trchová, Z. Morávková, I. Šeděnková, and J. Stejskal, "Spectroscopy of thin polyaniline films deposited during chemical oxidation of aniline," Chemical Papers, vol. 66, no. 5 , p. $415,2012$. 
[46] Z. Morávková, M. Trchová, M. Exnerová, and J. Stejskal, “The carbonization of thin polyaniline films," Thin Solid Films, vol. 520, no. 19, pp. 6088-6094, 2012.

[47] Z. Morávková, M. Trchová, E. Tomšík, J. Čechvala, and J. Stejskal, "Enhanced thermal stability of multi-walled carbon nanotubes after coating with polyaniline salt," Polymer Degradation and Stability, vol. 97, no. 8, pp. 1405-1414, 2012.

[48] Z. Morávková, M. Trchová, E. Tomšík, A. Zhigunov, and J. Stejskal, "Transformation of oligoaniline microspheres to platelike nitrogen-containing carbon," Journal of Physical Chemistry C, vol. 117, no. 5, pp. 2289-2299, 2013. 


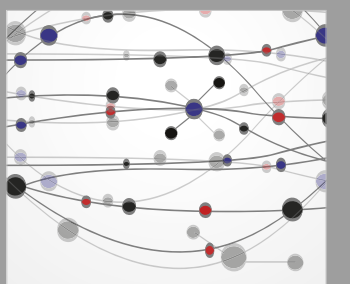

The Scientific World Journal
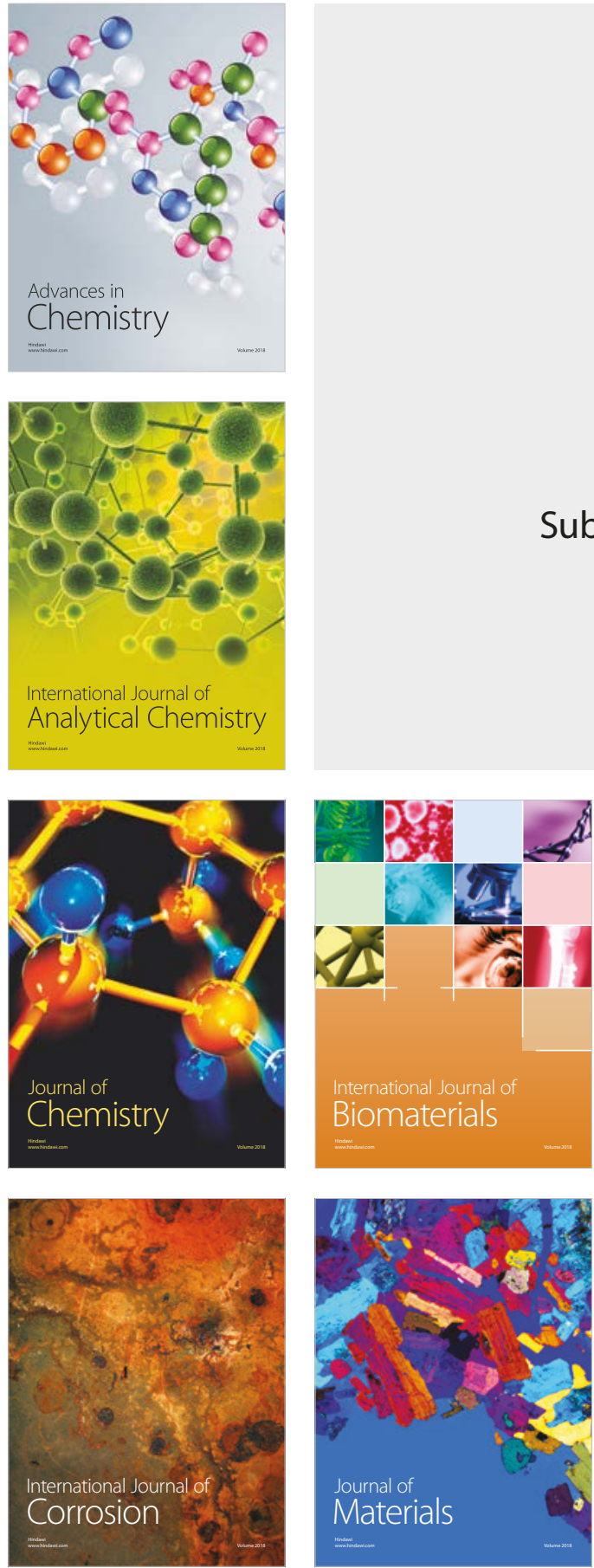

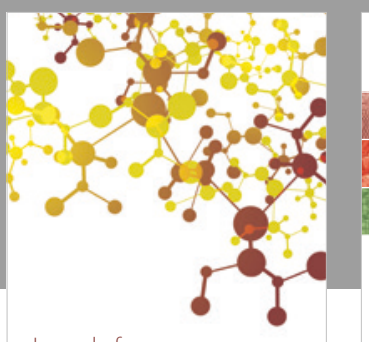

Journal of

Applied Chemistry
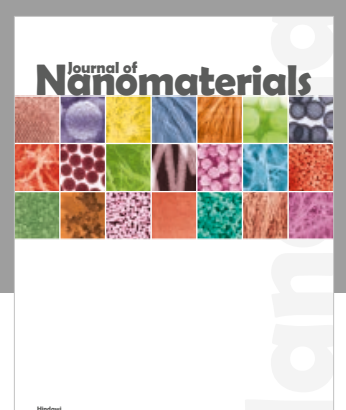

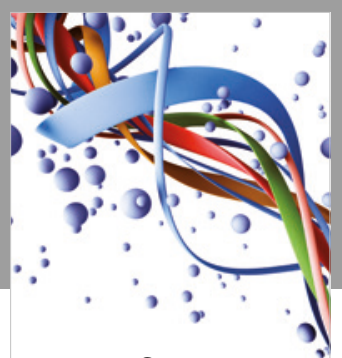

Scientifica

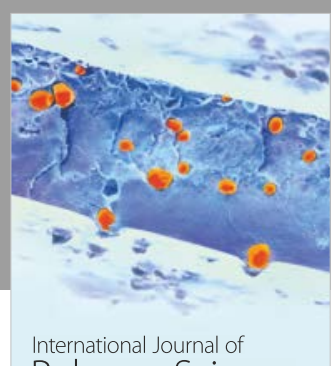

Polymer Science

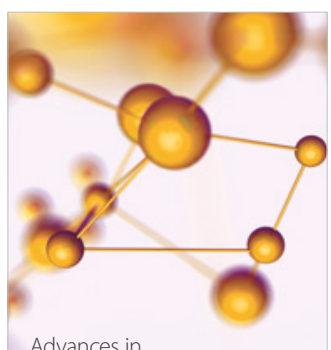

Physical Chemistry
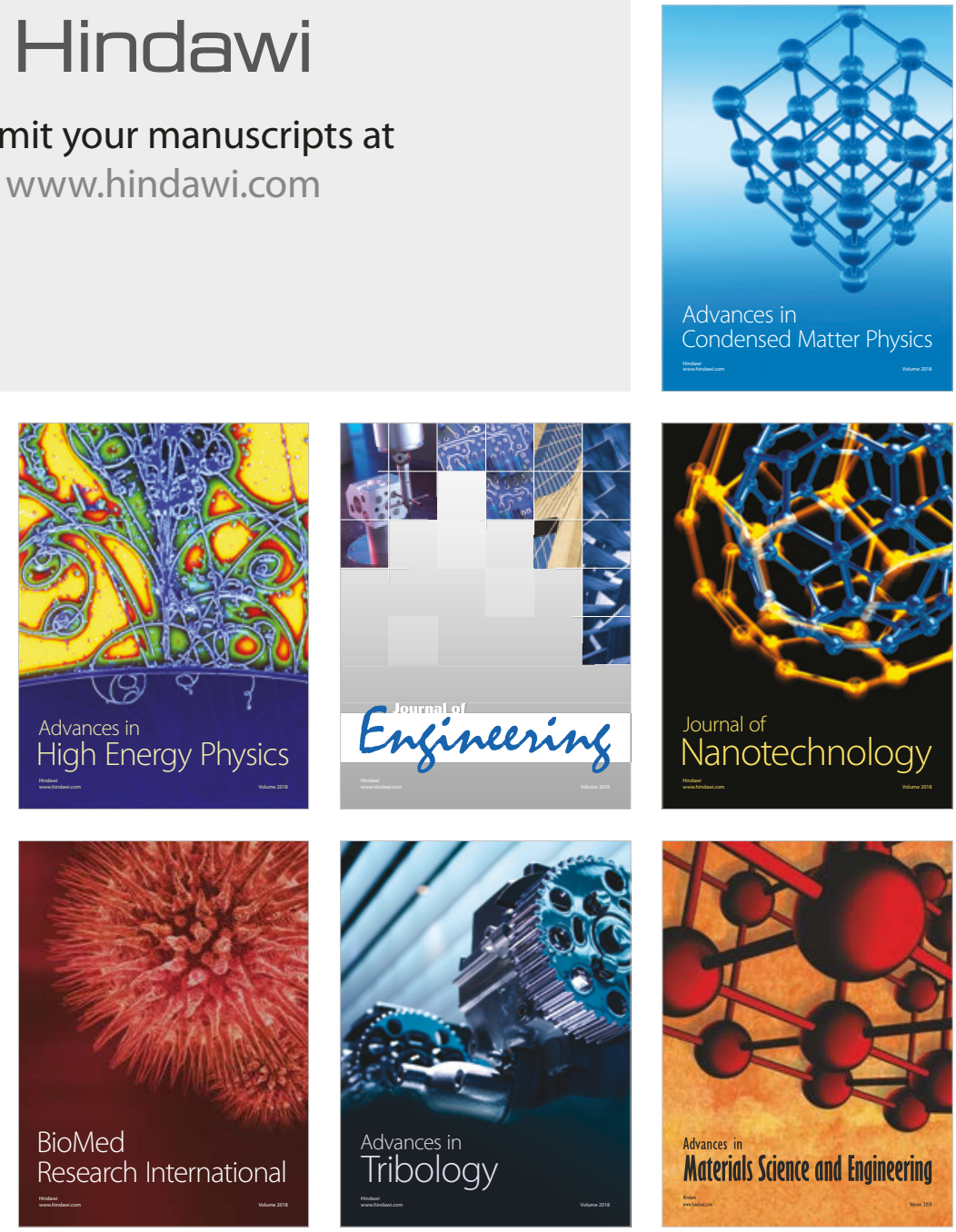